\title{
IDENTIFICAÇÃO DE GENÓTIPOS DE ALGODÃO (Gossypium spp.), QUANTO À PRESENÇA DE INIBIDORES DE PROTEASE
}

\author{
Identification of genotypes of cotton (Gossypium spp.), with relationship to \\ the presence of protease inhibitors
}

DanielleMarieMacedoSousa ${ }^{1}$

Ticiana Maria Lúcio de Amorim ${ }^{2}$

MaurícioPereiradeSales ${ }^{3}$

MárciaSoares Vidal ${ }^{4}$

\section{Resumo}

O objetivo deste trabalho foi verificar a presença e o índice de inibição dos inibidores de proteases presentes nas sementes de alguns genótipos do Banco Ativo de Germoplasma do algodão (Gossypium $s p p$.). $\mathrm{O}$ extrato protéico bruto das sementes de algodão foi quantificado quanto à concentração de proteínas totais e, seguidamente, testado para avaliação da atividade inibitória das enzimas tripsina e papaína. Os resultados foram expressos em atividade residual de tripsina e papaína, determinada pela absorbância a $440 \mathrm{~nm}$ contra os controles apropriados para cada reação. Assim, foi possível identificar a presença significativa de inibidores das enzimas tripsina e papaína nos extratos protéicos das sementes, tendo, em alguns genótipos, um índice de inibição acima de 70\%.

Palavras-chave: Algodão; Gossypium spp.; Sementes; Inibidores de proteases.

Bióloga, Mestranda em Agronomia, Programa de Pós-Graduação em Agronomia, Centro de Ciências Agrárias, Universidade Federal da Paraíba, Areia-PB. e-mail: daniellemariem@yahoo.com.br

Pós-Graduação em Bioquímica, Universidade Federal do Rio Grande do Norte, Natal-RN. e-mail: tici_amorim@yahoo.com.br

Prof. Dr., Universidade Federal do Rio Grande do Norte, Natal-RN. e-mail: msales@cb.ufrn.br

Pesquisadora Embrapa-Agrobiologia, Seropédica, RJ. e-mail:marcia@cnpab.embrapa.br 


\section{Abstract}

The objective of this work was to verify the presence and the index of inhibition of the proteases inhibitors presents in the seeds of some genotypes of the Active Bank of Germoplasm of the cotton (Gossypium sp p.). The protein extract rude of the cotton seeds was quantified with relationship to the concentration of total proteins and tested for evaluation of the inhibitory activity of the enzymes tripsin and papain, The results were expressed in residual activity of tripsin and papain, certain for the absorbance to $440 \mathrm{~nm}$ against the appropriate controls for each reaction. Like this, it was possible to identify the significant presence of inhibitors of the enzymes tripsin and papain in the protein extracts of the seeds, tends in some genotypes, an inhibition index above $70 \%$.

Keywords: Cotton; Gossypium spp.; Seeds; Protease inhibitors.

\section{Introdução}

O algodão é a fibra têxtil mais antiga e importante cultivada no mundo, sendo considerada a fibra vegetal mais utilizada pelo homem, cujo comprimento pode atingir $38 \mathrm{~mm}$ e, em decorrência das poucas exigências em solo e clima, pode ser produzido e cultivado em todos os continentes (1). A sua fibra é a principal matéria-prima utilizada na confecção de vários tipos de tecido para a tecelagem e fios para a obtenção de feltro, de celulose, películas fotográficas e chapas para radiografia (2). Além dos benefícios obtidos pela utilização da fibra, pode-se aproveitar, também, as propriedades da semente do algodão, rica em óleo e útil para a alimentação humana e para a fabricação de margarina e sabão. O subproduto da extração do óleo (torta) também pode ser útil para a alimentação animal (1).

Na agricultura, o controle de pragas/doenças faz parte do sistema de produção de uma cultura, uma vez que, sem o seu controle, esses inimigos tendem a diminuir muito a produtividade de uma lavoura; entretanto, o controle das pragas requer, para sua execução, conhecimentos sólidos sobrea morfologia, biologia, hábitos das pragas, além dos danos e sintomas de ataque delas. Devido ao ataque de pragas e doenças, a perda da produção agrícola mundial tem sido estimada em $37 \%$, dos quais $13 \%$ causados por insetos (3). Os métodos convencionais empregados para a proteção das culturas são por meio de agroquímicos, porém seu uso aumenta consideravelmente os custos de produção e pode causar desequilíbrio no ambiente, decorrente dos resíduos. Existe grande dificuldade em se manter a estabilidade da produção algodoeira, em virtude do ataque das pragas, uma vez que, para combatêlas, faz-se necessário o consumo de cerca de $25 \%$ de todo o inseticida gasto no planeta.

Visando a obter um desenvolvimento sustentável desse agroecossistema, há necessidade da implementação de práticas capazes de minimizar os riscos de danos causados por pragas e do acréscimo de outros benefícios, como: uso mais eficiente de praguicidas; menores riscos de intoxicação humana; minimização dos índices de contaminação ambiental; preservação da biodiversidade; menores possibilidades de resistência aos praguicidas e maior rentabilidade, devido à redução dos custos e à subseqüente manutenção dos rendimentos (3).

Uma dessas características importantes para o agronegócio do algodão é o desenvolvimento de genótipos resistentes/tolerantes aos insetos/praga; esses genótipos podem ser obtidos por meio de plantas transformadas com genes de interesse, como, por exemplo, os genes que codificam inibidores de proteases.

Os inibidores de proteases constituem-se em um elemento dentre os vários mecanismos vegetais de defesa contra insetos herbívoros. As plantas possuem certo grau de resistência a insetos e apenas um número limitado destes é hábil a alimentarem-se de cada espécie. Essa resistência inerente é baseada nos vários mecanismos de defesa desenvolvidos pelas plantas, durante a evolução. Atualmente, sabe-se que os defensivos são encontrados em vários tecidos vegetais e expressos constitutivamente e outros podem ser induzidos por lesões (4). Diversas plantas, como a batata e o tomate, sintetizam esses inibidores, em resposta ao ataque de insetos. A presença dos inibidores nas folhas pode acarretar a morte de insetos herbívoros, por má nutrição, em conseqüência da inibição das suas proteases digestivas (5).

Plantas, microrganismos e animais contêm proteínas que apresentam a propriedade de formar complexos proteína-proteína, reversíveis ou não, com várias enzimas proteolíticas, promovendo a inibição da atividade dessas proteases por competição pelo seu sítio catalítico. Estas proteínas são moléculas cuja massa molecular varia de 10 a $90 \mathrm{kDa}$, na maioria dos casos (6). São denominados de acordo com a protease inibida e/ou sua fonte como, por exemplo, o inibidor de tripsina de soja [Glycine max (L.) Merril] (7).

Os inibidores de proteases mais conhecidos e estudados são aqueles que afetam a atividade de serino- 
proteases, cisteínoproteases, proteases aspárticas e metaloproteases, que são os quatro grandes grupos aos quais pertencem as enzimas proteolíticas (8). Os inibidores de tripsina, uma serino-protease, concentra o maior número de pesquisas no assunto, sendo as famílias Solanaceae, Leguminosae e Gramineae as mais investigadas quanto à atividade de inibidores, por representarem importantes fontes de alimentos (6). Neste contexto, o objetivo deste trabalho foi verificar a presença de inibidores de proteases e o índice de inibição deles, presentes nas sementes de alguns genótipos do Banco Ativo de Germoplasma do algodão(Gossypium spp.).

\section{Material e métodos}

\section{Material Vegetal}

As sementes de algodão empregadas neste trabalho foram obtidas junto ao Banco Ativo de Germoplasma de Algodão - BAG (Tabela 1) da Embrapa Algodão, situada no município de Campina Grande, PB. Essas sementes foram trituradas para a obtenção da farinha.

Tabela 1 - Lista dos genótipos de algodão testados para a identificação de inibidores de proteases

\begin{tabular}{ll}
\hline Genótipos & Espécie \\
\hline FMT 97-1067 & \\
Precoce 1 & \\
Delta Opal & \\
ITA 90 & \\
Stoneville 132 & \\
Tamcot Spinks & \\
CNPA 5M & \\
CAB-CS & Gossypium hirsutum
\end{tabular}

Sto 474

BRS Antares

Allen Ancien

BSA T92

Acala Ancien

Tashkent

Triumph big

Sea Blang

Bahtium 110

Giza 79

Gossypium barbadense

Mono 79

Boumi dgiroff

AK-4 Gossypium herbaceum

Boumi Ghermer

Colunam

Lao $1 / 85$

Desi 627

Gossypium arboreum

AK 235

G 117-2 


\section{Delipidação das farinbas das sementes de algodão}

A delipidação das farinhas dos genótipos de algodão selecionados foi realizada pelo método de Soxhlet, segundo a metodologia descrita em (9) e citada por (10). Fez-se a trituração $20 \mathrm{~g}$ de farinha, previamente pesada em balança de torsão semianalítica (METTLER ${ }^{\grave{O}}$ ), modelo P1210, em cartucho próprio de extração. Os lipídios foram extraídos pela utilização de hexano (30-60 $)$, em seguida, a farinha foi retirada do cartucho, hábil para a obtenção dos extratos protéicos.

\section{Obtenção dos extratos protéicos das sementes de algodão}

Para a extração das proteínas, foi pesada $1 \mathrm{~g}$ de cada farinha das sementes de algodão previamente delipidada. Em seguida, $10 \mathrm{~mL}$ de tampão Tris- $\mathrm{HCl}$ pH 7,5 $50 \mathrm{mM}$ foi adicionado à farinha, e incubado sob agitação por uma hora, à temperatura ambiente. Decorrido esse tempo, a suspensão foi centrifugada por 30 minutos a $4^{\circ} \mathrm{C}$, sob rotação de $15.000 \mathrm{rpm}$. Após a centrifugação, o sobrenadante foi coletado em tubo Falcomä de $15 \mathrm{~mL}$ e filtrado em lã de vidro, mantido sob refrigeração $\left(-20^{\circ} \mathrm{C}\right)$ até a sua utilização nos testes de atividade inibitória.

\section{Determinação da atividade nibitória de extratos protéicos de sementes de algodão contra tripsina}

O extrato protéico bruto, das sementes de algodão, foi quantificado quanto à concentração de proteínas totais e, seguidamente, testado para a avaliação da atividade inibitória de tripsina. Para a obtenção da curva de inibição, o volume de $200 \mu \mathrm{L}$ do extrato bruto foi incubado com $15 \mathrm{~mL}$ de tripsina do pâncreas bovino, com $165 \mathrm{~mL}$ de volume de tampão Tris- $\mathrm{HCl} 50 \mathrm{mM}$ pH 7,5 e com $120 \mathrm{~mL}$ da solução ativadora $(\mathrm{HCl} 0,0025 \mathrm{M})$, até se atingir um volume final de $200 \mathrm{~mL}$ por tubo. A mistura foi incubada por $15 \mathrm{~min}$ a $37^{\circ} \mathrm{C}$ e $200 \mathrm{~mL}$ do substrato azocaseína foi adicionado em cada tubo. A incubação procedeu-se por mais 30 min a $37^{\circ} \mathrm{C}$ e a reação foi finalizada pela adição de $300 \mu \mathrm{L}$ de TCA $20 \%$ (v/v). As reações foram realizadas em triplicata, tanto para cada dose testada do extrato protéico quanto para os respectivos controles, os quais constavam da adição de ácido acético antes do substrato. Em seguida, após a interrupção da reação, as amostras foram retiradas do banho-maria e deixadas em temperatura ambiente, por cerca de 10 minutos, para então serem centrifugadas. Após a centrifugação, fez-se a retirada de $500 \mathrm{~mL}$ do sobrenadante, para outros tubos de vidro, com intuito da reação ser alcalinizada com $\mathrm{NaOH} 2 \mathrm{~N}$, na proporção de $1: 1$. O controle representando por $100 \%$ da atividade enzimática foi obtido pela mistura de reação sem a presença do extrato de proteínas (11). Os resultados foram expressos em atividade residual da enzima tripsina, determinados pela absorbância a 440 nm contra os controles apropriados para cada reação.

\section{Determinação da atividade inibitória de extratos protéicos de sementes de algodão contra papaína}

O extrato protéico bruto das sementes de algodão foi quantificado quanto à concentração de proteínas totais e testado para a atividade inibitória da papaína. Para cada genótipo, foram utilizadas três repetições, sempre com o controle, que foi o parâmetro útil para avaliação da atividade inibitória dos extratos. O controle da enzima papaína e das três repetições também foi utilizado como foi todo o procedimento, em tubos de hemólise.

Inicialmente, foram adicionados nos tubos $20 \mu \mathrm{L}$ da enzima papaína ( $1 \mathrm{mg}$ de papaína/ $2 \mathrm{~mL}$ de Tris-HCl $50 \mathrm{mM} \mathrm{pH} \mathrm{7,5),} \mathrm{juntamente} \mathrm{com} 40 \mu \mathrm{L}$ da solução ativadora (20 mM de EDTA; $25 \mathrm{mM}$ de bMercaptoetanol; Tris-HCl $50 \mathrm{mM} \mathrm{pH} \mathrm{7,5)} \mathrm{e} 40 \mu \mathrm{L}$ do tampão Tris- $\mathrm{HCl} 50 \mathrm{mM}$ pH 7,5, e só assim incubados a $45^{\circ} \mathrm{C}$, durante 10 minutos; após este tempo, foram adicionados $410 \mu \mathrm{L}$ de tampão Tris- $\mathrm{HCl}$ $50 \mathrm{mM} \mathrm{pH} \mathrm{7,5} \mathrm{no} \mathrm{controle} \mathrm{das} \mathrm{enzimas} \mathrm{e} 210 \mu \mathrm{L}$ no restante dos tubos; em seguida, foi adicionado $200 \mu \mathrm{L}$ dos extratos protéicos, com exceção dos tubos contendo as enzimas.

Todos os tubos foram incubados durante 10 minutos, a $45^{\circ} \mathrm{C}$, para posterior adição de $200 \mu \mathrm{L}$ de azocaseína a $1 \%$, com exceção dos controles. Novamente uma incubação de 10 minutos foi necessária para a adição de $300 \mu \mathrm{L}$ de TCA $20 \%$ e 200 $\mu \mathrm{L}$ de azocaseína $1 \%$ nos controles, a fim de promover a interrupção da reação. As amostras foram retiradas do banho-maria e deixadas à temperatura ambiente durante cerca de 10 minutos e centrifugadas. A partir dos sobrenadantes obtidos, $500 \mu \mathrm{L}$ foram transferidos 
para tubos de hemólise para serem alcalinizados com $\mathrm{NaOH} 2 \mathrm{~N}$, na proporção de 1:1. O controle representando $100 \%$ da atividade enzimática foi obtido pela mistura de reação sem a presença do extrato de proteínas (11). Os resultados foram expressos em atividade residual da enzima papaína, determinados pela absorbância a $440 \mathrm{~nm}$ contra os controles apropriados para cada reação.

\section{Resultados e discussão}

Dos genótipos do banco de germoplasma do algodão testados, observa-se que todos os extratos protéicos demonstraram capacidade de inibir proteases serínicas, assim como proteases cisteínicas. Verificaramse, quando da realização dos testes de inibição com os extratos protéicos das sementes de algodão contra a enzima comercial tripsina, uma variação na taxa de inibição com mínimo de $8,13 \%$ no genótipo Lao $1 /$ 85 e um máximo de $89,04 \%$ em Bahtium 110. Os genótipos FMT 97-1067, Sea Blang, Mono-79, Precoce 1 e G117-2 apresentaram, respectivamente, as seguintes porcentagens de inibição: $71,20 \%$, $74,85 \%, 76,21 \%, 75,43 \%$ e $85,75 \%$ (Figura 1). Essas taxas de inibição indicam que os extratos protéicos são inibidores de proteases serínicas, podendo ser utilizados no futuro, para inibir a ação de enzimas de diversos insetos/praga, principalmente lepidópteros possuidores da digestão facilitada pelas proteases serínicas, existentes em seu intestino médio (5); além disso, também podem atuar na defesa contra patógenos, tendo como exemplo a inibição da atividade tripsínica do fungo Rhizoctonia solani Kuhn(12).

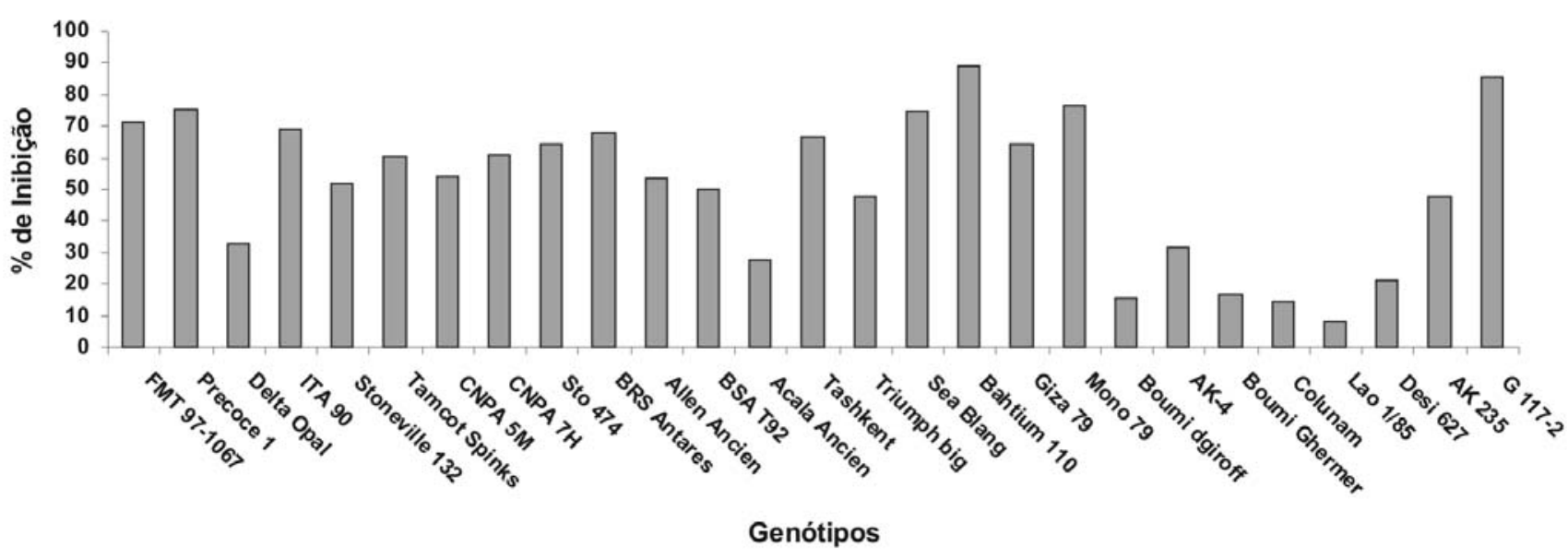

\section{Figura 1 - Inibição da atividade tripsínica pelos extratos protéicos totais de alguns genótipos do BAGda Embrapa-Algodão}

Os inibidores de tripsina concentram o maior número de pesquisas no assunto, sendo as famílias Solanaceae, Leguminosae e Gramineae as mais investigadas quanto à atividade de inibidores, por representarem importantes fontes de alimentos (6). $\mathrm{O}$ gênero Gossypium spp, pertencente à família Malvaceae, também mostrou representativa atividade inibitória contra a tripsina, enfatizando os genótipos da espécie Gossypium barbadense, que possuem maior capacidade de inibir, acima de 70\%, a enzima tripsina, como em Bahtium, Sea Blang e Mono 79.
A triagem das sementes de algodão quanto à inibição de proteases cisteínicas também foi bastante significativa, visto que mostrou inibição satisfatória da enzima papaína, com expressivos valores acima de $70 \%$, como em Delta Opal, com índice de 90,33\%. O valor mínimo encontrado foi em Precoce 1, com 32,72\% de inibição. Os genótipos CNPA 5M, Desi 627, Stoneville 132, Lao 1/85, Mono 79, Sto 474, AK 4, ITA 90 e BST 92, apresentaram respectivamente inibição de 70,51\%, $74,20 \%, 75,58 \%, 76,50 \%, 81,11 \%, 81,57 \%, 81,57 \%$, $84,80 \%$ e $88,95 \%$ (Figura 2 ). 


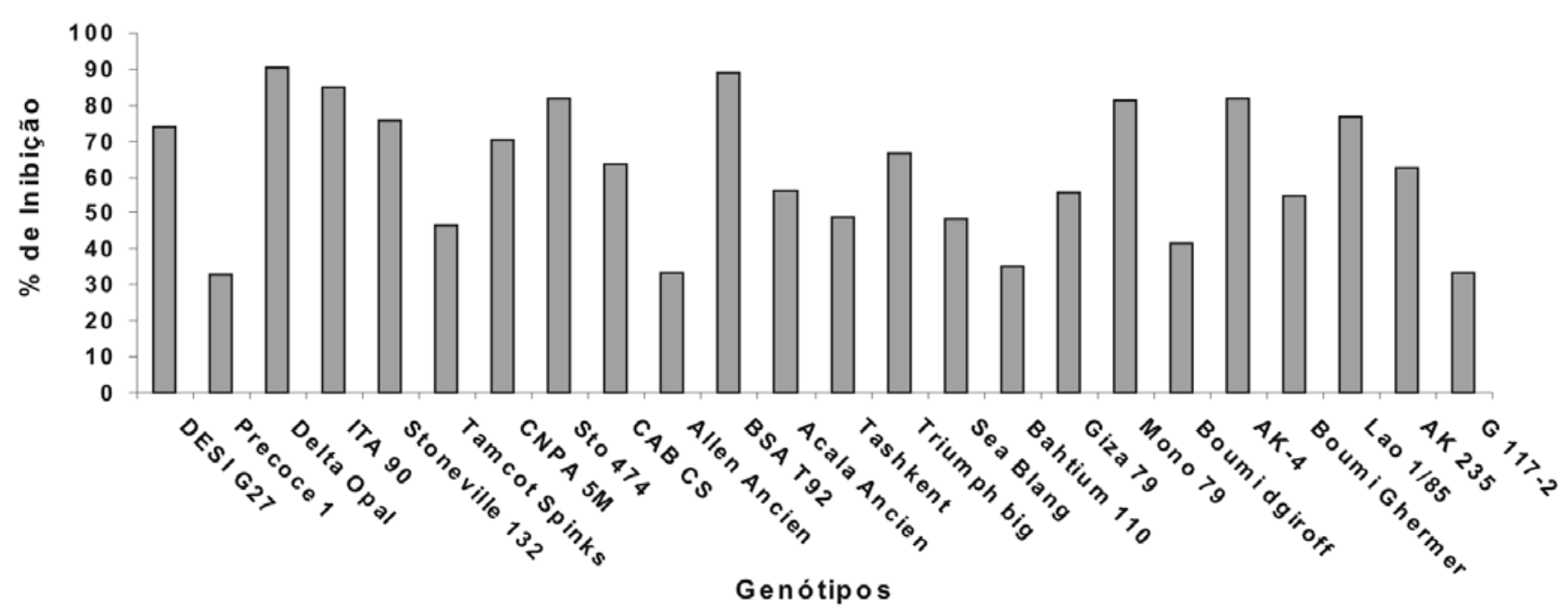

\section{Figura 2 - Inibição da atividade papaínica pelos extratos protéicos totais de alguns genótipos do BAGda Embrapa-Algodão}

Ressalta-se que grande parte dos extratos protéicos que demonstraram inibir a papaína comercial faz parte da espécie Gossypium hirsutum (Delta Opal, Stoneville 132, Sto 474, CNPA 5M, BST 92 e ITA 92), a qual representa cerca de $90 \%$ do algodão cultivado comercialmente. A taxa de inibição dos extratos protéicos de algodão contra a enzima papaína é significantemente alta, superando os valores encontrados nos testes com a enzima tripsina, que se mostraram bastante significativos, assim evidenciando que a especificidade da inibição é consideravelmente variável. Alguns inibidores de proteases são capazes de inibir apenas uma protease, enquanto outros são ativos contra diferentes enzimas, dentro ou não de uma mesma classe (13). Resultados satisfatórios também foram encontrados em sementes maduras de Castanea sativa com significante atividade antipapaína de 44\% (14).

Atualmente, plantas transgênicas resistentes a diversas pragas, por meio da expressão de inibidores específicos para as enzimas proteolíticas digestivas desses insetos, são comercializadas e cultivadas. Alguns exemplos são as culturas de tabaco (Nicotiana tabacum L.), tomate (Lycopersicon esculentum L.), algodão(Gossypium hirsutum L.), batata (Solanum tuberosum L.), alfafa (Medicago sativa L.), canola (Brassica napus L.), soja (Glycine max), milho (Zea mays L.) e arroz (Oryza sativa L.) (15). Conhecendo melhor o papel de inibidores de proteases nas interações com insetos herbívoros e microrganismos, plantas geneticamente modificadas poderão ser obtidas para a expressão de genes que codifiquem inibidores específicos para proteases para o controle de pragas e doenças.

\section{Conclusões}

- a presença de inibidores de proteases cisteínicas no extrato protéico das sementes de algodão foi bastante expressiva contra a enzima comercial papaína, já que todos os genótipos testados mostraram alto potencial inibitório;

- o índice mais elevado de inibição foi avaliado na cultivar Delta Opal, com 90,33\%;

- os extratos protéicos também apresentaram inibição significativa à enzima comercial tripsina, com o valor máximo de $89,40 \%$ na cultivar Bahtium 110.

\section{Agradecimentos}

À EMBRAPA - ALGODÃO e à Universidade Federal do Rio Grande do Norte (UFRN), pela infra-estrutura necessária para a realização deste trabalho.

\section{Referências}

1. Richetti A, Melo Filho GA. Aspectos econômicos do algodoeiro. In: Algodão: tecnologia de produção. Campo Grande: Embrapa Agropecuária Oeste; Campina Grande: Embrapa Algodão; 2001. p. 13-34. 
2. Díaz NAA. El cultivo del algodón: apuntes basicos. Nicarágua. UMA; 1993.

3. Silva CAD. Microorganismos entomopato-gênicos associados a insetos e ácaros do algodoeiro. Campina Grande: Embrapa-CNPA; 2000. (Embrapa-CNPA Documentos, 77).

4. Fosket DE. Plant growth and development: a molecular approach. Academic Press; 1994.

5. Broadway RM. Dietary regulation of serine proteinases that are resistant to serine proteinase inhibitors. Journal of Insect Physiology. 1997; 43:855-874.

6. Richardson M. Seed storage proteins: the enzyme inhibitors. Methods in Plant Biochemistry. 1991; 5:259-305.

7. Kunitz M. Crystalline soybean trypsin inhibitor. Journal of Genetic and Physiology. 2004; 30:291-310.

8. Laskowsky M, Kato I. Protein inhibitors of proteinases. Annual Review of Biochemistry. 1980; 49:593-626.

9. AOCS. Official methods and tentative methods of the American Oil Chemists' Society. $3^{\text {rd }}$ ed. Champaign; 1976.
10. Freire RMM. Estudo de aminoácidos em genótipos de amendoim (Arachis hypogaea L.). 1997. [dissertação]. João Pessoa: Universidade Federal de Paraíba; 1997.

11. Lin JY, Chu SC, Wu HC, Hsieh YS. Trypsin inhibitor from the seeds of Acacia confusa. Journal of Biochemistry. 1991;110:879-883.

12. Tremacoldi CR, Pascholati SF. Detection of trypsin inhibitor in seeds of Eucalyptus urophylla and its influence on the in vitro growth of the fungi Pisolithus tinctorius and Rhizoctonia solani. Brazilian Journal of Microbiology. 2002; 33:281-286.

13. Weder JKP. Nutritional and toxicological significance of enzyme inhibitors in plant foods. In: Friedman, M. editor. Insect Phisiology. New York: Plenun Press; 1986. p. 299-347.

14. Pernas M, Sánches-Monge R, Gómez L, Salcedo G. A chestnut seed cystatin differentially against cysteine proteinases from closely related pests. Plant Molecular Biology. 1998; 38:1235-1242.

15. Jouanin L, Bonade-Bottino M, Girard C, Morrot G, Giband M. Transgenic Plants for Insect Resistance. Plant Science. 1998; 131:1-11.

Recebido em/Received in: July 28, 2006 Aceito em/Accepted in: August 31, 2006 